\title{
Por uma teoria do som no cinema de horror ${ }^{1}$
}

\author{
Rodrigo Carreiro \\ Universidade Federal de Pernambuco
}

\section{Resumo}

É voz comum entre pesquisadores do cinema que o papel do som nos filmes de horror é mais importante do que em outros gêneros fílmicos. O objetivo deste artigo é compreender por que o horror favorece mais o uso criativo do som do que outros tipos de filmes. Levando em consideração a relação estreita entre tecnologia e estética sonora, tentaremos identificar e analisar as principais tendências estilísticas, além dos mais recorrentes padrões de utilização de voz, efeitos sonoros e música - a fim de traçar apontamentos iniciais que permitam o desenvolvimento de uma base conceitual para a concepção de uma teoria do som no cinema de horror.

\section{Palavras-chave}

Horror; sound design; voz; efeitos sonoros; música.

\section{Introdução}

A cena apresenta o típico final do dia de uma família suburbana tradicional nos Estados Unidos. O pai (Craig Nelson), ausente, continua no trabalho, mas a mãe (JoBeth Williams) já deu conta de tudo: colocou pijamas no casal de filhos e deixou-os no quarto, prontos para dormir. Ela mesma toma um longo banho na banheira. Sem aviso prévio, porém, um ataque de seres fantasmagóricos, agressivos e repugnantes desmonta a tranquilidade da família. O garoto é atacado por um boneco de palhaço, a menina presencia a aparição de luzes e sons vindos da porta de um armário. E a mãe esbarra no esqueleto de animal que solta berros guturais ensurdecedores ${ }^{2}$.

A sequência, presente no filme de horror sobrenatural Poltergeist (Tobe Hooper, 1982), usa o contraste entre o silêncio do cotidiano e o barulho ensur-

1 Uma primeira reflexão sobre o tema foi publicado no número 24 da revista Ciberlegenda (Universidade Federal Fluminense), em 2011. Este artigo, apresentado no InsólitoCom - I Colóquio de Estudos do Horror e do Insólito na Comunicação (29 a 31 de outubro de 2018, Universidade Anhembi Morumbi, São Paulo) expande e atualiza o texto anterior em múltiplas direções.

2 A cena completa pode ser vista aqui: https://youtu.be/siyrG9aVz6U.

Revista Ícone (ISSN 2175-215X) • DOI: 10.34176/icone.v17i3.240271

Recife, Vol. 17, N. 3, 251-269, ๑ 2019 PPGCOM/UFPE.

Artigo recebido em 26 mar. 2019 e aprovado em 12 ago. 2019. 
decedor de um caos inesperado modulando essa transição de modo cuidadoso. E oferecendo uma oportunidade de observar todos os principais padrões de estilo que fazem do horror um "gênero primordialmente baseado no som" (HUTCHINGS, 2004, p. 128): ruídos inesperados e fora do quadro, música dissonante e atonal gritos, vozes guturais e respirações ofegantes são alguns dos eventos sonoros que constituem convenções do horror - elementos presentes num grande número de filmes do gênero.

Se aceitarmos que há uma estreita conexão entre o som e o horror, então é possível conceber uma teoria a respeito do uso do som no gênero, a partir de uma pergunta central: por quais razões o horror favorece mais o uso criativo do som do que outros tipos de filmes? Esta é a questão que vamos abordar neste artigo, cujo objetivo é desenvolver alguns apontamentos para a construção de uma base conceitual que permita a concepção de uma teoria do som no cinema de horror.

Ao longo do percurso, usaremos como fio condutor a sequência paradigmática de Poltergeist, que reúne praticamente todos os padrões de estilos sonoros cujas presenças em filmes de horror acontece em larga escala. Desse modo, pretendemos identificar e catalogar as principais técnicas utilizadas pelos cineastas na construção estilística do horror através do som. As ferramentas estilísticas que descreveremos são utilizadas com mais frequência nesse gênero do que em outros? Quais elementos da linguagem musical são empregados de forma recorrente pelos compositores que escrevem músicas para filmes de horror? Que técnicas de concepção, criação, edição e mixagem de efeitos sonoros, ruídos e ambientes são mobilizadas com mais consistência pelos editores, mixadores e sound designers que trabalham com o gênero? Há modos específicos de uso da voz que aparecem mais frequentemente no horror? E de que forma as tecnologias digitais de gravação, edição, mixagem e reprodução sonora interferem na manipulação de sons para filmes de horror? Este artigo tenta oferecer respostas a essas perguntas através de uma análise estilística do som em filmes de horror.

A identificação e reflexão sobre os principais padrões de estilo recorrentes no horror nos permitirá analisar os motivos pelos quais essas técnicas se tornaram populares entre os realizadores. Esse percurso, não necessariamente cronológico, levará em consideração ainda a relação estreita entre a tecnologia e a estética sonora dos filmes, já que alguns dos padrões mais discerníveis no horror contemporâneo só foram possibilitados pela introdução de inovações técnicas na cadeia produtiva do audiovisual, como é o caso do sistema de redução de ruídos criado pela Dolby Laboratories, e disponibilizado para a indústria cinematográfica em 1975; e dos sistemas de reprodução com canais surround ${ }^{3}$, como o Dolby Stereo (1975, um canal surround), Dolby Digital (1992, dois canais surround) e Dolby Atmos (2012, que pode chegar a dezenas de canais surround).

3 Os canais surround têm sons reproduzidos por alto-falantes posicionados ao lado e atrás da plateia. Reproduzem, portanto sons cujas origens diegéticas estão fora do campo visual. 


\section{O som e o horror}

O horror só começou a ser reconhecido como gênero cinematográfico, pela crítica e pelo público, após o sucesso alcançado por Drácula (Tod Browning, 1931) e Frankenstein (James Whale, 1931). Os títulos inauguraram o ciclo de filmes de monstros da Universal, e foram lançados poucos meses após o circuito exibidor da época ter equipamentos capazes de projetar películas sincronizadas com trilhas sonoras pré-gravadas. Drácula foi exibido pela primeira vez em 14 de fevereiro de 1931, enquanto Frankenstein foi lançado em 21 de novembro do mesmo ano. Peter Hutchings (2004, p. 128) argumenta que o deslanchar do primeiro ciclo de produção devotado ao horror e a popularização do cinema sonoro ${ }^{4}$ não foi mera coincidência: "desde o princípio, o gênero [do horror] tem oferecido aos cineastas oportunidades de explorar inúmeras possibilidades trazidas por novas tecnologias sonoras" (HUTCHINGS, 2004, p. 128).

Um breve olhar retrospectivo demonstra que o som sincronizado e o horror se beneficiaram um ao outro. Com as vozes, músicas e efeitos sonoros encorpando as imagens e lhes dando vida, a mobilização afetiva da plateia em direção às sensações fisiológicas relacionadas ao sentimento do horror - um elemento central para a eficiência dos filmes do gênero, como atesta Noël Carroll (1999) - se tornou mais efetiva, transformando a experiência de assistir a um filme do gênero em algo mais visceral e impactante. Este raciocínio ajuda a explicar por que o horror se tornou um dos primeiros gêneros a tomar corpo na era de ouro do cinema norte-americano ${ }^{5}$.

O ponto de partida deste artigo consiste em providenciar uma definição estável do horror como gênero narrativo. Como toda categoria taxonômica do audiovisual, o horror possui fronteiras elásticas e dinâmicas. Rick Altman (1999), Steven Neale (2000) e Mark Jancovich (2002), entre outros teóricos, têm reconhecido esse fato:

Elementos como a performance dos atores, a forma de exibição, distribuição e consumo dos filmes, o padrão de produção, as ideias aludidas na divulgação (cartazes, entrevistas dadas à imprensa, releases, trailers, teasers etc.) e vários outros começaram também a ser levados em consideração no estudo dos gêneros, que deixaram de ser vistos como categorias estáveis para se tornarem configurações discursivas em permanente recombinação

4 A maioria dos livros que contam a história do cinema de horror consideram, atualmente, que o expressionismo alemão foi o primeiro dos ciclos de produção cinematográficos ligados ao horror. No entanto, essa associação só começou a ser feita a partir da publicação do almanaque An Illustrated Story of Horror Films, de Carlos Clarens, em 1967.

5 O período vai aproximadamente do início do cinema sonoro (1927) até o final da segunda guerra mundial (1945). 
e subdivisão, tendo em vista, mais do que uma forma fixa, um processo que se dá no âmbito da relação entre os produtores e a audiência, em permanente negociação (JANCOVICH, 2002, p. 1).

Noël Carroll (1999) destaca dois elementos como fundamentais para demarcar as fronteiras do gênero. Em primeiro lugar, para ser considerado horror, um filme precisa provocar na plateia o afeto que empresta seu nome ao gênero: as pessoas devem ficar horrorizadas (ou, pelo menos, estarem dispostas a isso) ao assistir a um filme de horror. Com esse critério, vários outros estudiosos do horror a exemplo de Carol Clover (1993), Mark Jancovich (2002) e Peter Hutchings (2004) - concordam. Ele tem importância fundamental para nosso estudo, uma vez que a maioria dos recursos estilísticos sonoros recorrentes no cinema de horror são empregados pelos cineastas e sound designers com o objetivo primário de provocar, na plateia, emoções e sensações relacionadas ao afeto do horror.

O segundo critério determina que um filme de horror precisa conter criaturas que Carroll chama de "monstros" (CARROLL, 1999, p. 29). Carroll considera como monstros apenas seres sobrenaturais, que não pertencem ao universo em que vivemos. A opinião dele não é unânime. Outros teóricos, como Carol Clover (1993), recusaram ou alargaram esse conceito, incluindo nele seres humanos capazes de atos repugnantes de violência, como assassinos seriais, animais gigantescos e outros.

Poderíamos, então, definir o conceito de monstro, para efeito de classificação de um filme no gênero do horror, como um ser que pode ou não pertencer à realidade física do mundo que habitamos, mas precisa cometer atos de violência que provoquem na plateia o afeto do horror. E o que seria exatamente esse afeto? Nas palavras de Carroll (1999, p. 41), experimentamos o afeto do horror quando sentimos uma combinação de medo e repugnância.

Quando uma pessoa se vê diante de um momento de horror, na vida real ou diante de um filme, o evento (na forma de estímulos audiovisuais) toma dois caminhos através do cérebro, que o neurocientista Joseph E. LeDoux chama de "caminho superior" e "caminho inferior" (...). O primeiro caminho busca uma compreensão consciente do evento, por meio de percepção e avaliação intelectual. O segundo conecta o momento do horror ao corpo físico (através da amígdala - um depósito de medos primais e memórias emocionais), que desencadeia uma descarga de adrenalina, respiração rápida, pressão arterial e frequência cardíaca elevadas. (WHITINGTON, 2014, p. 176). 
Portanto, o filme de horror ativa sensações físicas e sentimentos, muitas vezes com uma potência que outros gêneros não conseguem atingir. Nesse sentido, é correto afirmar que, tratado estilisticamente a partir de certos padrões recorrentes de som, imagem e enredo, o horror deve evocar visualidade e auralidade hápticas (MARKS, 1999; QUINLIVAN, 2011; COULTHARD, 2012), e adequar-se com eficiência a noção de cinestesia ${ }^{6}$ desenvolvida por Vivian Sobchack (2004): o filme não é apenas visto e ouvido, mas experimentado com o corpo inteiro. E os padrões estilísticos do som representam papéis importantes nessa construção afetiva.

\section{A voz no filme de horror}

Para refletir sobre padrões de estilo que aparecem de forma frequente nessas produções, vamos tratar do som dos filmes a partir de cada um dos três componentes da banda sonora, conforme a divisão de trabalho estabelecida em Hollywood desde 1934 (CARREIRO, 2018, p. 54): vozes, efeitos sonoros e música. Iniciamos nossa reflexão pelos padrões de uso da voz, porque pertence a esta categoria o mais frequente e reconhecível padrão recorrente de uso do som no horror: o grito.

De fato, o grito constitui a representação sonora mais concreta do sentimento de horror; aparece em praticamente todos os títulos do gênero e, mais importante, surge como um dos elementos fundamentais para provocar na plateia o afeto horrorífico, sendo de importância crucial para confirmar o pertencimento ao gênero. Há uma razão, de cunho cognitivo, para que o grito tenha se tornado a mais reconhecível marca sonora do filme de horror: ele estimula fortemente a identificação entre o personagem-vítima e o espectador. $\mathrm{O}$ grito do personagem simboliza a sensação de horror que ele está sentindo, e que passa a ser paralelamente percebida também pelo espectador.

$\mathrm{Na}$ sequência de Poltergeist, o grito domina toda a segunda parte da sequência, a partir do ataque do boneco de palhaço ao garoto (Oliver Robins). Tanto ele quanto a mãe, que é erguida até o teto por forças invisíveis, gritam de horror durante todo o ataque. No final da sequência, a mãe apresenta ainda uma segunda modalidade de grito, quando tenta acessar o quarto das crianças e é barrada por um monstro: ela berra em direção ao ser sobrenatural, desafiando-o e seguindo o instinto maternal de proteger os filhos. Temos, então, gritos que expressam a natureza do horror sentido pelos personagens (e compartilhado pelos espectadores), além de gritos que respondem à ameaça, denotando raiva. Ambos são respostas acústicas para impulsos cognitivos, intuitivos e irracionais do ser humano.

6 O neologismo combina a palavra sinestesia (uma sensação sentida por mais de um sentido fisiológico) com cinema, e mais outros dois termos da biologia (synaesthesia e coenaesthesia) que designam estruturas do aparelho sensório do ser humano. Desde então, a noção de cinestesia tem sido usada na teoria do cinema como sinônimo de narrativa audiovisual que evoca sensações fisiológicas e táteis, se possível empregando vários sentidos simultaneamente. 
O grito, junto com uma série de outros ruídos vocais de natureza não semântica - a respiração, os gemidos, a tosse, o suspiro, a gargalhada, o choro e outros -, tem sido pouco discutido nos estudos de som para cinema. Essas vocalizações são cruciais para as diversas modalidades de cinema que valorizam impulsos sensórios (ELSAESSER, 2015; LUCA, 2015; VIEIRA JR, 2015). O conteúdo não semântico da voz contribui decisivamente para criar uma empatia e uma engajamento afetivo entre a plateia e os seres da ficção (QUINLIVAN, 2011; COULTHARD, 2012), ajudando os espectadores a não apenas apreciar a trama, mas experimentá-la afetiva e sensorialmente.

A presença, em primeiro plano sonoro, da respiração dos personagens, com variados graus de ênfase, é uma tendência proeminente nos filmes de horror contemporâneos, como confirmado por editores de som e mixadores brasileiros como Ricardo Cutz, Bernardo Uzeda, Daniel Turini, Gera Vieira, Justino Passos e Débora Opolski, todos entrevistados sobre o assunto (CARREIRO, 2019). A respiração amplia a conexão afetiva entre membros da plateia e personagens da ficção, podendo denotar raiva, tensão e medo com enorme intensidade. R. Murray Schafer (2001, p. 317) observou que, em muitos casos, espectadores podem passar a respirar, inconscientemente, no mesmo ritmo de personagens. A presença da respiração interfere decisivamente no ritmo narrativo de uma produção audiovisual.

É importante destacar que, no horror, o uso do grito nos filmes já antecipava essa tendência desde os primórdios. Em entrevista ao repórter Thomas K. Arnold (2008), o historiador George Feltenstein afirma que a imagem de uma mulher gritando, em filmes vinculados a temas do horror, já era comum antes mesmo de 1927, ano que o som sincrônico pré-gravado começou a ser reproduzido nas salas de projeção.

Mencionar a importância do grito para o gênero também significa lembrar o termo scream queens (em tradução literal, "rainhas do grito"). A expressão tem sido utilizada por estudiosos de horror desde a primeira década do cinema sonoro. O termo surgiu nos anos 1930, com o intuito de caracterizar as atrizes que participavam de muitos filmes do gênero, quase sempre como vítimas do monstro (ou assassino). Essas atrizes, muitas vezes, eram escaladas para produções de horror por causa da textura e do timbre de suas vozes, em geral agudo, o que sugeria fragilidade e docilidade.

A primeira 'rainha do grito' popular foi a atriz Fay Wray. Ela ficou famosa por causa dos gritos de pavor emitidos ao longo de King Kong (Merian C. Cooper e Ernest B. Schoedsack, 1933). Nos anos seguintes a produção, Wray participou de diversos outros filmes semelhantes, sendo escalada com frequência para papéis que exigiam o exercício de seu talento vocal peculiar. Outras 'rainhas do grito' dignas de menção foram Beverly Garland (nos anos 1950), Neve Campbell (anos 1990), Elisha Cutberth e Kate Beckinsale (anos 2000) - as duas últimas agraciadas com o troféu de melhor grito em uma premiação especializada em filmes de horror, distribuída em Los Angeles (EUA) e denominada (não por coincidência) Scream 
Awards ${ }^{7}$.

A mais popular de todas as 'rainhas do grito', provavelmente responsável pela popularização definitiva do termo entre o público aficionado, foi a atriz Jamie Lee Curtis, protagonista de Halloween (John Carpenter, 1978). Curtis estrelou diversos filmes de John Carpenter e fez muitos filmes de horror nos anos 1980, mostrando sua marca registrada vocal em várias delas. Uma curiosidade extra é que, na vida real, Curtis era filha de outra 'rainha do grito' da década anterior: Janet Leigh, atriz que ganhou fama ao ser retalhada no chuveiro por Norman Bates, na famosa cena de Psicose.

Se o grito no filme de horror costuma estar associado diretamente aos personagens-vítima, outro uso recorrente da voz no gênero diz respeito aos ruídos vocais emitidos pelo monstro - a voz do agressor. Nesse ponto, é possível observar duas práticas de produção bastante comuns, dependendo da natureza do monstro. Nos filmes em que este tem origem natural e humana (serial killers, psicopatas etc.), é comum que sua voz tenha textura gutural, profunda, com timbre próximo ao limite de audição para baixas frequências percebido pelo ouvido humano. As pessoas conseguem escutar sons que variam entre 20 e $20.000 \mathrm{~Hz}$, sendo que a voz é emitida quase sempre dentro de um intervalo que varia entre 150 e $3400 \mathrm{KHz}$ (o timbre mais comum situa-se entre 300 e $1000 \mathrm{~Hz}$ ). Atores que interpretam vilões frequentemente falam em timbres situados por volta de 120 a $300 \mathrm{~Hz}$ - ou seja, possuem vozes que, no universo do canto lírico, seriam categorizadas como baixos ou barítonos.

Foi por causa da voz grave e gutural que o ator norte-americano Vincent Price se consagrou como um dos mais importantes vilões da história do cinema de horror, interpretando uma grande variedade de bruxos, assassinos, psicopatas e cientistas loucos em mais de 50 longas-metragens. A mesma trajetória marcou a carreira do britânico Christopher Lee, que interpretou monstros como Drácula, Frankenstein e a Múmia em filmes da produtora inglesa Hammer, no final dos 1950 e início dos anos 1960.

Assim como Price, Lee se especializou involuntariamente em interpretar vilões do cinema de horror. O filão não foi uma escolha direta de nenhum dos dois atores. As características físicas das duas vozes - timbre, textura e profundidade - foram determinantes nas oportunidades profissionais que se apresentaram a ambos.

Nos casos em que o monstro tem origem não-natural, e especialmente quando sua aparência é humanoide (demônios, fantasmas, extraterrestres, criaturas mitológicas ou sobrenaturais etc.), o uso de texturas guturais é igualmente corriqueiro. É o que ocorre na cena de Poltergeist que conduz este texto: o monstro que aparece diante da porta do quarto das crianças, para impedir a mãe de entrar lá e tentar protegê-las, assume a forma do gigantesco esqueleto de um animal de quatro patas - e seus rugidos poderosos são sons de frequência abaixo de $200 \mathrm{~Hz}$,

7 Em tradução literal, Prêmio Grito. 
surgindo muitas vezes como estrondos graves que ecoam no subwoofer ${ }^{8}$.

As emissões vocais dos vilões também são, muitas vezes, alteradas digital ou eletronicamente, ou apareçam ainda como um produto da sobreposição de várias vozes guturais e rugidos de animais. A voz do psicopata Leatherface, em $O$ Massacre da Serra Elétrica, foi sobreposta a grunhidos de porcos (WHITINGTON, 2004, p. 182). A voz da garota possuída em O Exorcista talvez seja o exemplo mais conhecido dessa prática recorrente de uso da voz no cinema de horror. Nesse filme, que concretizou uma convenção para muitos filmes de horror baseados em possessões demoníacas, a apresentação de vozes guturais, dissonantes e/ou sobrepostas produz um estranho efeito de descorporificação do personagem - a textura da voz parece antinatural para o corpo do qual ela sai - que enfatiza a repulsa, um dos elementos centrais do afeto do horror.

Não é difícil explicar a preferência por vozes com baixas frequências reforçadas para os personagens antagonistas do horror cinematográfico. Se os timbres agudos e doces de tenores ou sopranos sugerem mansidão, tranquilidade e espírito frágil, a textura grave dos barítonos e baixos possui semelhança acústica com os urros selvagens e grunhidos agressivos produzidos pelas cordas vocais dos animais, em particular aqueles maiores, mais perigosos e imprevisíveis. Trata-se de uma convenção que não surge aleatoriamente, como mero clichê narrativo, mas possui origem em processos cognitivos de percepção inerentes à espécie humana.

\section{Efeitos sonoros em destaque}

Desde meados dos anos 1970, tecnologias de reprodução sonora permitem que os sons envolvam o espectador por inteiro, colocando-o em uma posição espacial que lhe permite sentir-se dentro, e não apenas diante, da diegese (KERINS, 2010, p. 130). Dentre os três componentes do som de filmes (vozes, ruídos, música), foi o segundo - os efeitos sonoros - que mais se beneficiou desse novo contexto tecnológico. Comentando sobre a hierarquia dos componentes da banda sonora, que tradicionalmente privilegiava a voz desde a instituição do re-recording system ${ }^{9}$, William Whitington (2014) sugere que o horror é o único gênero fílmico no qual os efeitos sonoros possuem mais destaque estético e narrativo do que a voz e a música:

Durante o período clássico, a hierarquia tradicional assegurava que os efeitos sonoros deveriam ser apenas funcionais e discretos, ajudando a estabelecer a sensação

8 Alto-falante específico para emissão de sons graves, que ativam tanto o tato (pois reverberam na caixa torácica dos indivíduos) quanto a audição.

9 Este conjunto de procedimentos técnicos estabelecia que a voz dos atores deveria ser captada isoladamente, durante as gravações, e que todos os outros sons oriundos da diegese deveriam ser reconstruídos durante a pós-produção (BUHLER, NEUMEYER, DEEMER, 2010, p. 310). 
de continuidade ininterrupta. No entanto, no cinema de horror contemporâneo, o oposto é verdadeiro. (...) os efeitos sonoros tornaram-se uma forma de espetáculo em si, em especial depois do surgimento dos sistemas de reprodução multicanal e de redução de ruídos, demandando mais atenção aos espectadores. (WHITINGTON, 2014, p. 180).

A primeira das tecnologias multicanais a que Whitington (2014) se refere, e que elevou os efeitos sonoros a um patamar de destaque na banda sonora, foi o Dolby Stereo. O sistema, lançado em 1975, unia na verdade duas tecnologias em torno do objetivo de obter maior fidelidade e dinâmica sonora - a distância entre os sons mais delicados e os sons mais ruidosos que um sistema consegue reproduzir - na reprodução dos sons gravados. O Dolby Stereo continha dois canais de áudio que, através de um complicado processamento eletrônico, era capaz de gerar quatro canais (três dianteiros e um surround, reproduzido dos lados e atrás da sala) contendo diferentes sons. O sistema também contava com um sistema de redução dos ruídos de fundo, o que permitia que a faixa dinâmica atingisse $50 \mathrm{~dB}$, mais do que o dobro do alcançado pelos antigos sistemas monocanais.

Nas décadas seguintes, surgiram outros sistemas de reprodução multicanal, a partir de tecnologias digitais, como o Dolby Digital (lançado em 1991) e o Dolby Atmos (2012). Nesses sistemas, em que o número de alto-falantes pode variar de seis a 128, a quantidade de eventos sonoros capazes de serem reproduzidos em grande variedade, complexidade e fidelidade acústica foi expandido enormemente. Ao mesmo tempo em que o ruído de fundo praticamente chegou a zero, de forma que a distância entre o silêncio da sala de projeção e o volume mais alto pode chegar a $100 \mathrm{~dB}$ (quatro vezes mais do que o Dolby Stereo).

As tecnologias sonoras multicanais digitais incluem características técnicas que favorecem de muitas maneiras os filmes de horror. Além de permitir, através de uso agressivo da dinâmica sonora - um sussurro delicado pode ser sucedido por um grito poderoso - sustos de grande impacto afetivo, a redução dos ruídos da projeção permite que pequenos sons delicados, como a já citada respiração, amplifiquem a mobilização sensorial e cinestésica dos corpos da plateia. Por fim, os múltiplos alto-falantes localizados nas laterais, na traseira, no teto e no chão das salas de exibição permitem que os sons fora de quadro sejam utilizados para ampliar ainda mais a tensão dos espectadores, por sugerir de modo mais complexo e modulado a presença de seres ameaçadores fora do campo visual.

Gianluca Sergi (2006) sugere que os efeitos sonoros são processados pelos espectadores, do ponto de vista cognitivo, de maneira sensorial, sem passar por filtros intelectuais; uma pessoa vendo um filme raramente tem consciência crítica a respeito dos ruídos que preenchem a trilha sonora, pois sua atenção está concentrada em acompanhar a evolução da narrativa, o que se dá primordialmente através de diálogos e imagens. Muitos cineastas perceberam que podiam causar 
reações afetivas e sensoriais manipulando os sons - em especial, os sons fora de quadro, que Michel Chion (2008, p. 31) denominou de "acusmáticos", pois não vemos sua origem.

Ao compreender o potencial dos efeitos sonoros para mobilizar afetivamente os espectadores, através de uma variedade de técnicas que podiam incluir a audição de um ruído inesperado (susto), o deslocamento no espaço de sons cuja origem é, ou pode ser, ameaçadora (tensão), e o retardamento do processo de identificação de um determinado som com o objeto, ser ou fenômeno físico que lhe origina (suspense), entre outras, os cineastas podem modular o afeto do horror com grande precisão. Essas tecnologias, como Sergi (2006) observa, abriram caminho para a liberação completa desse potencial.

O raciocínio nos leva a afirmar que o cinema de horror, mais do que filmes de qualquer outro gênero, dá a oportunidade aos diretores de usar o som fora de quadro em um modo que Michel Chion chamou de "ativo". Segundo Chion, a maior parte dos filmes usa os sons fora de quadro de modo passivo, pois "cria uma ambiência que envolve a imagem e a estabiliza, sem suscitar o desejo de ir ver noutro lado ou antecipar a visão da sua fonte; portanto, de mudar de ponto de vista" (CHION, 2008, p. 70-71). As tecnologias digitais, como o Dolby Atmos, reforçaram o uso dessa técnica.

A construção narrativa de uma cena com sons fora de quadro dessa natureza é chamada por ele de "passiva". Pois bem: no cinema de horror, como vimos, um padrão recorrente estabelece, como técnica para gerar medo, tensão, suspense e em última instância o próprio afeto do horror, o uso de sons "que levantam questões - o que é? O que se passa? - que procuram respostas no campo [quadro] e incitam o olhar a ir ver" (CHION, 2008, p. 70). São os sons fora de quadro ativos. Portas rangendo, janelas batendo, grunhidos de animais e gritos de pavor estão entre os sons fora de quadro mais comumente utilizados em filmes de horror.

O som fora de quadro ativo foi explorado de maneira mais explícita e criativa nos filmes produzidos por Val Lewton para os estúdios RKO, ao longo dos anos 1940. Peter Hutchings (2004, p. 137) destaca que o uso dessa ferramenta estilística se tornou uma marca registrada dos longas-metragens desenvolvidos por Lewton, independentemente do diretor com que ele trabalhava, e acabou por influenciar decisivamente o trabalho dos sound designers que trabalhavam com o cinema de horror, a partir dos anos 1950. Sangue de Pantera (Cat People, Jacques Tourneur, 1942) é apontado como filme pioneiro em sugerir acontecimentos, através de sons que narravam cenas inteiras sem que se pudesse ver nada do que acontecia.

$\mathrm{Na}$ cena de Poltergeist, os sons fora de quadro marcam o início efetivo do ataque das forças sobrenaturais contra a família Freeling. Quando as duas crianças estão prestes a pegar no sono e a câmera focaliza o rosto do garoto Robbie, de olhos fechados, podemos ouvir a pancada de uma queda, seguida do arrastar no chão de um objeto pesado. Robbie também ouve esse som, cuja origem não é mostrada. Ele se senta na cama e olha para a cadeira vazia diante dela, onde estava localizado o boneco de palhaço, mostrado com destaque no princípio da cena. $\mathrm{O}$ boneco 
não está mais lá. Assustado, Robbie olha embaixo da cama, mas nada encontra. Quando se levanta, porém, tem o pescoço agarrado pelo palhaço, que agora está na cama com ele, e pode se mover. Os sons fora de quadro não despertaram apenas a curiosidade de Robbie; eles o fizeram sentir medo e tensão - sentimentos compartilhados pela plateia.

Outro filme importante na história do cinema de horror que dá destaque especial aos sons fora de quadro é Desafio ao Além (The Haunting, Robert Wise, 1963). Esse filme é particularmente inovador, na área dos efeitos sonoros, porque o monstro - o vilão - jamais aparece: trata-se de um fantasma que habita uma grande mansão vitoriana em Londres, para onde se muda uma equipe multidisciplinar que pretende estudar os fenômenos paranormais registrados na casa. Em Desafio ao Além, o verdadeiro vilão é o som fora de quadro, em si mesmo. Sem realizar aparição, o fantasma se manifesta arranhando as paredes, batendo portas e janelas, chacoalhando lustres e provocando ruídos diversos.

O filme de Robert Wise também funciona como exemplo de outra ferramenta narrativa característica do cinema de horror: o uso do efeito sonoro como leitmoti $v^{10}$, que assinala a presença do monstro sem mostrá-lo. Em geral, o leitmotiv costuma ser um tema ou fraseado musical, mas no cinema de horror essa peça sonora que indica a presença do monstro é com frequência um efeito sonoro, tal como um assobio ou um zumbido de baixa frequência.

Um exemplo recente está em Atividade Paranormal (Paranormal Activity, Oren Peli, 2007), filme em que o monstro jamais aparece em imagens. Antes de cada evento estranho atribuído à entidade sobrenatural, o espectador pode ouvir um zumbido grave, captado pela câmera que o casal protagonista sempre deixa ligada. Além disso, o criativo conceito de som do filme cuida para que o zumbido, mesmo sendo um evento sonoro simples e sutil, se manifeste de maneira sobrenatural, porque nas salas de cinema ele pode ser ouvido através dos canais surround, enquanto todos os demais sons do filme surgem apenas nos alto-falantes dianteiros - da forma que uma câmera caseira os capturaria. Assim, o filme antecipa os eventos mais assustadores através de um efeito sonoro que anuncia a presença do vilão, ao mesmo tempo em que amplia a tensão e dispara uma reação afetiva da plateia conectada ao sentimento do horror.

Outro padrão recorrente no cinema de horror é o uso do som para realçar, acentuar ou provocar o que alguns pesquisadores chamam de efeito-surpresa, ou "startle effect" (BAIRD, 2000, p. 15) - uma técnica que na música é conhecida como stinger. Nessa técnica, a justaposição entre um instante muito silencioso e um som alto e vibrante (uma porta batendo, um grito, uma nota musical etc.) induz a um momento em que o espectador toma um susto e salta da cadeira.

Segundo Robert Baird (2000, p. 15), a utilização típica dessa técnica exige três condições: (1) um personagem-vítima precisa estar em quadro; (2) a presença

10 Conceito de Richard Wagner, criado no século XIX, e que consiste em associar determinado som, musical ou não, a um personagem (ou grupo), sentimento ou situação dramática. 
de uma ameaça fora de quadro a esse personagem deve ser uma certeza ou uma presunção; (3) a irrupção súbita de uma figura nova dentro do quadro deve aproximar visualmente a vítima e um suposto agressor. Quando as três condições são reunidas, a cena resultante quase sempre provoca um susto no espectador - muitas vezes, esse susto é compartilhado com o personagem que está em quadro, o qual também não vê a aproximação do elemento ameaçador.

$\mathrm{Na}$ cena de Poltergeist, a aparição surpreendente do boneco de palhaço logo atrás do garoto Robbie, quando este se levanta depois de examinar embaixo da cama, ativa um efeito-surpresa que é sublinhado pela irrupção igualmente inesperada de um acorde intenso e agudo da música atonal de Jerry Goldsmith. Trata-se de um dos momentos mais esperados por qualquer fã de filmes de horror: a cena do susto chocante, que faz o espectador pular da cadeira, gritar e saltar.

Peter Hutchings (2004, p. 135) afirma que um dos primeiros longas-metragens a exibir uma cena de efeito-surpresa foi o já citado Sangue de Pantera (1942). Trata-se de um dos momentos mais conhecidos do clássico de Jacques Tourneur: Alice (Jane Randolph) está sendo perseguida por Irena (Simone Simon), uma exótica sérvia, numa rua escura e deserta, à noite. $\mathrm{O}$ espectador vê apenas Alice, mas está ciente da presença de Irena porque seus passos ecoam na calçada - o uso do som fora do quadro ativo é fundamental para gerar tensão e suspense. De repente, paramos de escutar os passos. Tanto Alice quanto a plateia sabem que a moça sérvia descende de uma família supostamente amaldiçoada, em que as fêmeas se transformam em panteras quando estão sob forte tensão sexual. A conclusão é clara: Irena acaba de sofrer uma transformação, que ocorreu fora de quadro, e a ameaça sobre Alice não apenas é real como o ataque pode acontecer a qualquer momento, já que não ouvimos mais o som dos passos de Irina na calçada para calcular a distância entre as duas personagens. De repente, sem aviso, o silêncio é rasgado por um rugido felino, que por sua vez se transforma, após uma fração de segundo, no som dos freios de um ônibus. O veículo para ao lado de Alice, que sobe nele e respira aliviada, suavizando também a tensão da plateia.

\section{A música dissonante}

A representação sonora do efeito-surpresa não está circunscrita aos ruídos. A função narrativa de aplicar sustos no espectador também pode ser alcançada através da música, que evidentemente tem outras funções, notadamente atuando como uma espécie de sinalizador afetivo para os membros da plateia.

$\mathrm{Na}$ música tradicionalmente feita para o cinema de horror, o efeito-surpresa está associado com frequência a técnica do stinger. A justaposição de um som (no caso da música, uma nota ou acorde), ouvido em volume muito mais forte do que aquele elemento sonoro escutado no instante anterior, provocando um súbito e inesperado crescendo sonoro - em geral, sincronizado com uma imagem que mostra a aparição abrupta dentro do quadro de um novo elemento visual que ameaça o personagem focalizado. A cena de encerramento de Carrie - A Estranha 
(Brian De Palma, 1976), em que duas mãos saem inesperadamente de um túmulo e agarram uma garota, apresenta um dos efeitos-surpresa musicais mais famosos do cinema.

Nesse sentido, vale a pena assinalar que a música do filme clássico de horror também é abundante em crescendos e glissandos, duas técnicas de execução menos utilizadas em filmes pertencentes a outros gêneros. No crescendo, como o nome indica, o compositor promove uma subida gradual de tons na escala musical; os glissandos são alcançados quando a passagem de uma nota a outra, num instrumento musical, é obtida de forma crescente. O famoso trecho executado com violinos, na cena do assassinato no chuveiro em Psicose, é um exemplo de execução de glissando para concretizar a realização do efeito-surpresa na música - nesse caso, um glissando extremamente agudo, em que os violinos soam como gritos e são ritmicamente executados como facadas, reforça a empatia entre espectador e vítima.

Um glissando bem diferente - grave, executado com a voz e percorrendo a escala musical no sentido decrescente - pode ser escutado na cena de abertura de O Iluminado (Stanley Kubrick, 1980), em que a família Torrance dirige até o Hotel Overlook. De modo geral, a música de O Iluminado tem enorme importância para o gênero do horror. Trata-se de uma composição dissonante, imprevisível: características que não deixam o espectador antever como as harmonias, cadências e melodias irão se completar. Parte da música veio da obra avant garde do compositor polonês Krzystof Penderecki. A outra parte abunda em notas soturnas, drones ${ }^{11} \mathrm{e}$ atmosferas criadas com sintetizadores eletrônicos pela compositora Wendy Carlos.

De fato, todas as técnicas musicais descritas aqui são recursos utilizados pela maioria dos compositores que atuam no cinema de horror por uma razão estilística mais ampla: o uso constante de dissonâncias para demarcar uma atmosfera de desequilíbrio, incompletude, instabilidade e estranheza. Mark Brownrigg (2003) explica que a razão para o uso frequente dessas técnicas na música escrita para filmes de horror é exatamente a mesma pela qual a atonalidade também aparece regularmente no gênero. A música atonal, que não possui um único centro tonal estável e não tem, portanto, uma tonalidade predominante, percorre a escala cromática como um nível de previsibilidade muito menor, o que acentua no espectador a sensação de instabilidade. As composições escritas por Jerry Goldsmith para Poltergeist, que abundam na segunda parte da cena condutora, fazem uso extensivo da atonalidade.

Nos filmes de horror em que o compositor opta por escrever a música de forma tradicional, com um centro tonal definido, outras técnicas são evocadas com certa frequência para produzir sensações de inquietude e incompletude. Explicando que a música ocidental oscila entre três modos de composição (em tom maior, em tom menor ou que exploram a dicotomia entre os dois modos), Brownrigg decreta que "no horror, o tom menor predomina, e frequentemente é utilizado

11 Um drone é um tema musical que consiste em uma nota solitária, prolongada indefinidamente, sobre a qual são sobrepostas outras notas, ou mesmo um tema musical, mas que não tem continuidade ou ritmo definidos. 
ao longo de toda a composição" (BROWNRIGG, 2003, p. 115). Em Halloween, embora o tom maior predomine ao longo do filme, a música que se ouve na cena final, quando o psicopata Michael Myers consegue escapar e continua ameaçando a heroína, reverte para o tom menor.

O princípio da dissonância na música de horror também pode ser perseguido através de técnicas não ortodoxas de execução de instrumentos, alterações artificiais de timbres através de manipulações eletrônicas dos sons e fragmentação melódica acentuada. No primeiro caso, podemos citar Poltergeist como exemplo (cordas de piano são percutidas com baquetas, címbalos são esfregados no concreto). Em O Iluminado, violinos são tocados com os dedos ao invés de arcos. Este último também apresenta exemplos de alterações eletrônicas de som, com uso constante de sintetizadores para alterar o timbre de instrumentos tradicionais, como o piano. No caso da fragmentação melódica, que Brownrigg (2003, p. 121) descreve como a utilização de trechos incompletos de melodias que dão a sensação de não terminar, um exemplo é A Cidade dos Amaldiçoados (Village of the Damned, John Carpenter, 1985).

O uso de certos acordes na música criada para filmes de horror também é bastante comum. Philip Tagg (2003, p. 190) observa que há séculos existem sons musicais que vêm sendo conotativamente identificados por ouvintes ocidentais, pelo menos desde o estabelecimento do estilo romântico na Europa, como representativos do sentimento do horror. Tagg menciona, entre outros, os acordes em tríade menor acrescidos de uma nota em sétima maior. Esse acorde é denominado por Kevin Donnelly (2005, p. 108), pesquisador da música ouvida em filmes de horror, como "acorde Hitchcock", por causa do uso frequente nas trilhas de Bernard Herrmann escritas para filmes do diretor inglês, incluindo a já citada passagem de Psicose. Na história da música ocidental, o trítono que contém a nota Fá sustenido (F\#) é chamado de diabolus in musica: esse intervalo chegou a ter o uso vetado aos compositores, pela Igreja Católica, por medo de que atraísse seres sobrenaturais quando executado.

Há outros exemplos. David Sonnenschein (2001, p. 121) menciona o uso de acordes em quinta diminuta como um padrão recorrente em filmes de horror porque, segundo ele, trariam conotativamente ao ouvinte sentimentos que evocariam ações de natureza demoníaca, malévola ou simplesmente horrorífica.

Entre as convenções musicais específicas do cinema de horror, estão as associações entre certos instrumentos e algumas convenções narrativas. $\mathrm{O}$ uso de harpas, celestas e coros infantis, como em A Sétima Profecia (The Seventh Sign, Carl Schutz, 1988) evoca a noção de algo celestial e muitas vezes sinaliza a presença de anjos ou enviados divinos. O canto gregoriano é muito usado em filmes de horror que lidam com a imagem do demônio, a exemplo de A Profecia (The Omen, Richard Donner, 1976). Violinos muitas vezes acompanham cenas de ataques de monstros, essencialmente porque o timbre do instrumento lembra gritos emitidos por seres humanos. Canções de ninar e melodias com timbre de caixinhas de música, predominantes na música ouvida em Os Inocentes (The Innocents, Jack Clayton, 
1961), preenchem outra convenção importante da música de horror, em que crianças de natureza ambígua podem incorporar ou personificar monstros.

É importante observar que a utilização abundante de canções populares nas trilhas sonoras de filmes, tendência que vem aumentando desde os anos 1960 (COOKE, 2008, p. 396), repercutiram com bastante saliência no uso da música dentro do cinema de horror. Nesse caso, a utilização de canções populares, em especial pertencentes ao rock'n'roll e ao heavy metal, tornou-se muito popular, e pode ser vista em filmes como Christine - O Carro Assassino (John Carpenter, 1983) e a refilmagem de Halloween (Rob Zombie, 2007). Três motivos explicam a predileção dos cineastas de horror por esses estilos musicais: (1) a empatia entre essa música e o público-alvo dos filmes, formado essencialmente por pessoas jovens, cujo gosto musical tende à música transgressora; (2) a natureza agressiva da música, que faz par com a agressividade natural do gênero fílmico; (3) muitos artistas de rock utilizam em discos e espetáculos a iconografia oriunda do imaginário do cinema de horror. Melodias de canções de rock costumam usar trítonos do tipo diabolus in musica com frequência.

Por fim, desde os anos 1970 é possível observar a uma tendência à dissolução da fronteira outrora rígida entre música e efeitos sonoros. Muitos pesquisadores têm escrito sobre essa tendência (KASSABIAN, 2003; SERGI, 2006; CARVALHO, 2009; BURWELL, 2013; OPOLSKI, 2013; SMITH, 2013; CARREIRO, BELTRÃO, 2014; GORBMAN in COSTA et al, 2016; PEREIRA, MIRANDA, 2016): as orquestrações sinfônicas de sabor neorromântico, tradicionais no cinema norte-americano desde a época do cinema silencioso, passaram gradualmente a perder espaço para temas musicais que valorizam mais a textura acústica dos sons, com influência bastante acentuada da música concreta $^{12} \mathrm{e}$ da música eletrônica ou eletroacústica.

Alguns dos primeiros filmes a experimentar com essas tendências podem ser encontrados no gênero do horror. É o caso de O Massacre da Serra Elétrica, no qual o próprio diretor, Tobe Hooper, e o músico experimental Wayne Bell criaram os temas musicais. Essa criação aconteceu em paralelo com a gravação do foley, de modo que a dupla gravou sons de instrumentos de percussão africana e ruídos resultantes da manipulação de objetos do cotidiano (moedas, ossos, vegetais), além de drones produzidos com a ajuda de um teclado eletrônico, e inseriu esses sons no filme. A ausência de padrões rítmicos e harmônicos contribui para que a experiência do filme seja crua - influenciada pela primeira geração de documentários filmados em $16 \mathrm{~mm}$ e com som direto gravado com gravadores portáteis (WHITINGTON, 2014, p. 173).

A tendência à dissolução de fronteiras entre efeitos sonoros e música tem levado muitos compositores contemporâneos a alterar seus métodos de trabalho. Johan Johansson, que escreveu a música original do filme de horror mãe! (mother!,

12 A música concreta, ou musique concrète, é um estilo no qual sons oriundos de objetos do cotidiano são apresentados como música; foi popularizado por Pierre Schaeffer, na França, durante a década de 1940. 
Darren Aronofski, 2017), pediu ao próprio diretor que a eliminasse, pois achou que ela retirava a dissonância que o filme pedia. Na sequência, ele contribuiu com a criação de efeitos sonoros não diegéticos - outra tendência estilística, notada por Jeff Smith (2013), muito presente em filmes de horror nos quais ouvimos frequentemente eventos sonoros que na vida real não possuem som, tais como sussurros de supostos fantasmas.

\section{Considerações finais}

A maior parte dos recursos estilísticos sonoros, que formam padrões recorrentes no cinema de horror, têm sido utilizados por realizadores, editores de som, mixadores, compositores e sound designers por um mesmo motivo, que consiste em ativar respostas afetivas e emocionais de medo, tensão e repugnância nos espectadores. Isso confirma a máxima de Peter Hutchings (2004), citada no início do artigo: o som é provavelmente mais importante para o horror do que para outros gêneros fílmicos, devido ao potencial que possui para a mobilização cinestésica (SSOBCHACK, 2004) da plateia.

Num gênero em que o ganha-pão dos membros da equipe técnica consiste em encontrar maneiras de fazer o espectador responder aos filmes usando todo o corpo, o uso cuidadoso das convenções sonoras se mostra essencial para o sucesso (criativo e financeiro). Por isso, é natural que o uso do som tenha uma unidade formal coesa.

Há, ainda, uma segunda razão que explica a importância aumentada das técnicas de construção sonora utilizadas nos filmes de horror. David Bordwell (2006, p. 52) afirma que muitos recursos estilísticos que renovam a poética cinematográfica têm origem dentro do cinema de gênero. O motivo é prosaico: o filme de gênero, em particular de horror, costuma ser encarado como uma espécie de cinema de segundo escalão, na hierarquia criativa dos estúdios e dos financiadores da indústria do audiovisual. Por isso, os diretores desses filmes têm mais liberdade para experimentar.

Bordwell menciona, ainda, um motivo final para explicar por que inovações estilísticas ousadas aparecem nos filmes de horror: esses títulos visam atingir um público-alvo mais jovem (e, por conta da idade, mais receptivo a inovações formais). Nos filmes de horror e thrillers de suspense, aos diretores e equipe técnica é permitido desenvolver novos recursos estilísticos e testá-los em filmes vistos por um público mais segmentado. Só depois de aprovados pelo público eles passam a ser adotados nas maiores produções.

\section{Referências}

BAIRD, Stuart. "The startle effect: implications for spectator cognition and media theory”. Film Quarterly, n. 53, v. 3, Los Angeles, 2000, p. 12-24. 
BORDWELL, David. The Way Hollywood tells it: story and style in modern movies. Los Angeles: University of California Press, 2006.

BUHLER, James; NEUMEYER, David; DEEMER, Rob. Hearing the movies: music and sound in film history. New York: Oxford University Press, 2010.

BURWELL, Carter. "No country for old music". The Oxford Handbook of new ausiovidual aesthetics (org. John Richardson, Claudia Gorbman, Carol Vernallis). New York: Oxford University Press, p. 168-170, 2013.

CARREIRO, Rodrigo; BELTRAO, Filipe Barros. "Ruídos na canção: o caso de Dançando no Escuro". Contemporânea, v. 12, n. 1. Salvador: Universidade Federal da Bahia, p. 288-304, 2014.

de Fantasia, 2019.

. a pós-produção de som no audiovisual brasileiro. João Pessoa: Marca CARVALHO, Márcia. "Anos 1070: O desenlace da polifonia tropical e a marginalia na música de cinema". Nas trilhas do cinema brasileiro (org. Rafael de Luna). Rio de Janeiro: Tela Brasilis Edições, v. 1, p. 84-95, 2009.

CHION, Michel. A audiovisão: som e imagem no cinema. Lisboa: Texto \& Grafia, 2008.

COOKE, Mervyn. A History of Film Music. Cambridge: Cambridge University Press, 2008.

COSTA, Fernando Morais; CARREIRO, Rodrigo; MIRANDA, Suzana Reck. "Uma entrevista com Claudia Gorbman". Rebeca - Revista Brasileira de Estudos de Cinema e Audiovisual, v. 5, n. 1, 2016, p. 170-188.

COULTHARD, Lisa. "Haptic aurality: resonance, listening and Michael Haneke". Film-Philosophy, v. 16, 2012, p. 16-29.

ELSAESSER, Thomas. "Cinema mundial: realismo, evidência, presença”. In: Realismo fantasmagórico (org. Cecília Mello). São Paulo: Pró-Reitoria de Cultura e Extensão Universitária da USP, 2015. pp. 37-60.

FELTENSTEIN, George. Entrevista. "Three screams for these stars". USA Today [jornal], 26/04/2007. Entrevista concedida a Thomas K. Arnold. Disponível em http://www.usatoday.com/life/movies/news/2007-04-26-scream-queens_N.htm. Acesso em 30/08/2018.

HUTCHINGS, Peter. The horror film. Edinburgh: Pearson Education Limited, 2004.

KASSABIAN, Anahid. "The sound of a new film form". Popular music and film. (org. Ian Inglis). London: Wallflower Press, p. 91-101, 2003.

KERINS, Mark. Beyond Dolby (Stereo): Cinema in the digital sound age. Bloomington: Indiana University Press, 2010.

LUCA, Tiago de. "Realismo dos sentidos: uma tendência no cinema mundial contemporâneo”. Realismo fantasmagórico (org. Cecília Mello). São Paulo: Pró-Reitoria de Cultura e Extensão Universitária da USP, p. 61-93, 2015.

OPOLSKI, Débora. Introdução ao desenho de som: uma sistematização aplicada na análise do longa-metragem ensaio sobre a cegueira. João Pessoa: Editora da UFPB, 2013. 
PEREIRA, Kira; MIRANDA, Suzana Reck. "Tão longe é aqui e a música dos ruídos: aproximações teóricas sobre aspectos do som no cinema contemporâneo". In: Rebeca - Revista Brasileira de Estudos de Cinema e Audiovisual, v. 5, n. 1. São Paulo: SOCINE, 2016, p. 170-188.

QUINLIVAN, Davina. The place of breath in cinema. Edinburgh: Edinburgh University Press, 2011.

Schafer, R. Murray. A afinação do mundo. São Paulo: Unesp, 2011.

SERGI, Gianluca. "In defense of vulgarity". Scope, v. 5, n. 1, 2006. Disponível em http://www.scope.nottingham.ac.uk/article.php?id=129\&issue $=5$. Acesso em 29/08/2018.

SMITH, Jeff. "The sound of intensified continuity". The Oxford Handbook of new audiovisual aesthetics (orgs. John Richardson, Claudia Gorbman e Carol Vernallis). New York: Oxford University Press, p. 331-356, 2013.

SOBCHACK, Vivian. Carnal Thoughts: Embodiment and Moving Image Culture. Berkeley: University of California Press, 2004.

VIEIRA JR, Erly. "Por uma exploração sensorial e afetiva do real: esboços sobre a dimensão háptica do cinema contemporâneo". Realismo fantasmagórico (org. Cecília Mello). São Paulo: Pró-Reitoria de Cultura e Extensão Universitária da USP, p. 93-113, 2015.

WHITINGTON, William. "Horror sound design". A companion to the horror film (org. Harry M. Benshoff). West Sussex: Wiley Blackwell, 2014, p. 168-185. 


\section{For a theory of sound in horror movies}

\section{Abstract}

It is a common voice among film researchers that the role of sound in horror films is more interesting than in other film genres. The main purpose of this article is to understand why horror favors the creative use of sound more than other types of movies. From this point of view, and always taking into account the close relationship between technology and sound aesthetics, we will try to identify and analyze the main stylistic tendencies and the most recurrent patterns of use of voice, sound effects and music in order to draw initial notes that allow the development of a conceptual basis for the conception of a sound theory in horror cinema.

\section{Keywords}

Horror. Sound design. Voice. Sound effects. Music.

\section{Sobre o autor}

Rodrigo Carreiro. Professor do Programa de Pós-Graduação em Comunicação da Universidade Federal de Pernambuco (UFPE). Mestre e Doutor em Comunicação pela UFPE.

rcarreiro@gmail.com 